\title{
Household Responses to Cash Transfers
}

\author{
BRAM DE ROCK \\ ECARES (European Center for Advanced Research in Economics and Statistics), \\ Université libre de Bruxelles \\ том РотомS \\ University of Sussex
}

DENN I TOMMASI

Monash University

\section{Introduction}

Over recent decades, conditional cash transfer (CCT) programs have occupied a large percentage of governments' annual antipoverty budgets (Fiszbein and Schady 2009). PROGRESA (Programa de Educacion, Salud y Alimentacion), a CCT program implemented in rural Mexico in the late 1990s, is a prime example in which the cash transfers are exogenously targeted to mothers in order to give them a higher share of the household resources. It has been well documented that these large monetary incentives have a substantial effect on household behavior; see Hoddinott and Skoufias (2004), Bobonis (2009), Attanasio and Lechene (2014), and Angelucci and Garlick (2016) for some recent empirical results.

We exploit the experimental setup of PROGRESA in order to structurally study how households respond to cash transfers in terms of the observed budget allocation of food. Focusing on the budget structure of food is a meaningful exercise as it accounts for around $80 \%$ of the expenditures of the targeted (poor) households in our sample. Moreover, Attanasio and Lechene (2014) convincingly show that the changes in food decisions are not solely influenced by the impact of the CCT on household income but are also due to changes in the intrahousehold decision process. In this paper, we want to further investigate

This is a substantial revision of an earlier paper that circulated under the same title. We have benefited from the comments of the editor, the associate editor, and two anonymous referees. We thank several participants at conferences and seminars for useful comments and suggestions. We acknowledge financial support from the Fonds National de la Recherche Scientifique (FNRS). All errors are our own. Contact the corresponding author, Bram De Rock, at bderock@ulb.ac.be. 
the latter, in particular, to further explain the gradual impact documented by Hoddinott and Skoufias (2004).

The starting point of our analysis of the intrahousehold decision process is the collective model of the household, which was pioneered by Chiappori $(1988,1992)$ and Apps and Rees (1988) and then further extended by Browning et al. (1994), Browning and Chiappori (1998), Blundell, Chiappori, and Meghir (2005), and Chiappori and Ekeland (2006). In recent years, this framework has become the main paradigm through which household allocation decisions are studied. There are two main reasons for this, and together they make the framework suitable to study the distributional impact of public policies. First, the fundamentals of the model — namely, individual preferences and the household decision process - can be identified under reasonable conditions (Chiappori and Ekeland 2009). Second, the model is based on a small set of assumptions, mainly the (Pareto) efficiency of the household allocation process, and yet provides strong testable restrictions. ${ }^{1}$

In this paper, we estimate a theoretically consistent demand system on different subsamples and apply a test of the collective model developed by Bourguignon, Browning, and Chiappori (2009). ${ }^{2}$ This test is based on so-called distribution factors that impact the household decision process but do not change the preferences or the budget constraint. It is appealing to apply data collected from randomized experiments to this $\mathrm{BBC}$ (Bourguignon, Browning, and Chiappori) test, because these programs allow researchers to construct, in principle, exogenous distribution factors. In what follows, we augment a structural QAIDS model à la Banks, Blundell, and Lewbel (1997) with two variables that the literature uses as credible distribution factors and estimate it on household budget shares of food. The first distribution factor that we use is the treatment indicator. For the second distribution factor, we follow Attanasio and Lechene (2014) by using data on the network of relatives present in the village. Subsequently, we run the $\mathrm{BBC}$ test by focusing on the most responsive demand equations with respect to the chosen distribution factors.

\footnotetext{
${ }^{1}$ See Bourguignon et al. (1993), Browning et al. (1994), Browning and Chiappori (1998), and Chiappori and Ekeland (2006) for testable implications in a parametric framework and Cherchye, De Rock, and Vermeulen $(2007,2009,2011)$ for a revealed preference approach.

${ }^{2}$ There is a long tradition testing the Pareto efficiency hypothesis (i.e., the main hypothesis of the collective model) in a household context. Early papers find efficiency in commodity demand (Bourguignon et al. 1993; Browning et al. 1994; Browning and Chiappori 1998), labor supply for childless couples (Chiappori, Fortin, and Lacroix 2002; Vermeulen 2005), children's health (Thomas, Contreras, and Frankenberg 2002; Duflo 2003), and female labor supply (Donni 2007; Donni and Moreau 2007). However, efficiency has been rejected in settings including household agricultural production (Udry 1996), labor supply for couples with children (Fortin and Lacroix 1997), and risk-sharing activities (Dercon and Krishnan 2000; Robinson 2012).
} 
Our estimates show that households satisfy the testable implications of the collective model only in 1998, 6 months after the beginning of the program, but reject them if we use the data 12 months after the first cash transfer. This implies that our results are different from the existing evidence in favor of the collective model (see Bobonis 2009; Attanasio and Lechene 2014) but are in line with Hoddinott and Skoufias (2004). Our more precise conclusion with respect to the importance of heterogeneity across time (in terms of efficiency) are explained by (i) our focus on food and (ii) the fact that our results are based on the inversion of the most responsive demand equations (see sec. V for more details). The latter makes our statistical tests much more powerful. ${ }^{3}$

In principle, the rejection of the BBC test of the collective model in the second period leaves open a multitude of possible explanations, including the validity of auxiliary assumptions, strategic behavior, or concerns about intertemporal commitment. However, as we discuss more in detail in section V.B, another possible explanation is that the PROGRESA program might not only impact the decision process (i.e., intrahousehold bargaining) but could also potentially affect individual preferences over the period of observation. A change in preferences implies that the treatment variable can no longer be interpreted as a proper distribution factor, which would impact only the decision process. This demonstrates once more the difficulty of finding exogenous distribution factors. As a result, the underlying assumptions of the BBC test are no longer valid, which may explain the rejection we find.

We like to highlight this alternative interpretation of changing preferences, given that it is in line with several pieces of existing evidence. First, and most importantly, there is ample empirical evidence of a change in preferences for different sorts of food items. Interestingly, as reported in Hoddinott and Skoufias (2004), the consumption of highly nutritious foods, such as fruits and vegetables, increased over and above the income effect only 12 months after the start of the program. This is exactly consistent with the horizon over which we find evidence against the collective model. Second, and related to this, the cash transfers are provided to women in conjunction with an intensive training aimed at empowering them on several dimensions (e.g., on the importance of good quality food but also on speaking up with respect to their rights). As it has been argued before, the impact of this training, which is a combination of more information and empowerment, takes place only gradually. Finally, survey questions in 1999 indicate that decision makers in households of the treatment group have

\footnotetext{
${ }^{3}$ In the appendix, we provide a comparison of the assumptions and statistical power across studies using PROGRESA data to test Pareto efficiency.
} 
statistically significant different aspirations and expectations than the control group. This indicates that cash transfers have second-round effects that may be directly interpreted as changes in preferences, particularly if these aspirations and expectations are related to (food) decisions with respect to the children.

Although it is well documented that PROGRESA is likely to have an overall positive effect on the welfare of children and the empowering of women in rural Mexico, our results also provide further evidence to think more carefully, both empirically and methodologically, about second-round effects of public interventions. ${ }^{4}$ As such, our paper is also related to the treatment effect literature of CCT programs, which aims at identifying empirical facts on how to obtain the desired policy interventions. One of the focuses of this literature is to establish whether, why, and to what extent targeting CCTs to women is effective (for a systematic review, see Yoong, Rabinovich, and Diepeveen 2012).

The rest of the paper is organized as follows. Section II describes the general theoretical framework, which motivates our empirical analysis. Section III discusses the data, the empirical strategy, and the methodological issues related to the estimation of a demand system. Section IV discusses our two potential distribution factors. Section $\mathrm{V}$ presents the results and motivates our interpretation in terms of changes in preferences. Section VI concludes.

\section{Theoretical Framework}

In this section, we discuss the theoretical setup of individuals' interactions within the household and introduce the test of the collective model that we run in the empirical section. Consider a household comprising two decision makers, $i=m, f$, and any number of children, where $m$ stands for mother and $f$ for father. Children are not part of the decision-making process and enter as a public good within the household. Household member $i$ cares about their own private consumption $\mathbf{c}^{i}$ and household public goods $\mathbf{k}$. Each member's preferences are assumed to be representable by a continuously differentiable and strictly concave utility function $U^{i}\left(\mathbf{c}^{i}, \mathbf{k} ; \mathbf{d}, \epsilon\right)$, where $\mathbf{d}$ and $\epsilon$ are a set of observable and unobservable characteristics that capture differences in preferences across individuals.

The resources of the family are derived from total household earnings $x$, potentially including an endowment entitled to member $m$. The budget constraint of the family can then be written as follows:

\footnotetext{
${ }^{4}$ Related to this, there is also empirical evidence that the program may have a negative impact by inducing a higher level of threats of violence and abuse of alcohol for some targeted households (see Angelucci 2008; Bobonis, González-Brenes, and Castro 2013; Bobonis, Castro, and Morales 2018).
} 


$$
\mathbf{p}^{\prime} \mathbf{c}+\mathbf{P}^{\prime} \mathbf{k}=x,
$$

where $\mathbf{p}$ and $\mathbf{P}$ are the price vectors of private and public goods, respectively.

As is standard in the literature on household consumption models (see, e.g., Chiappori and Mazzocco 2017), we assume that the household chooses a Pareto efficient allocation of resources. Furthermore, similar to Attanasio and Lechene (2014), we impose the widely used assumption of separability between food consumption and other (in particular, public) expenditures. ${ }^{5}$ This implies we assume that households solve the following (static) optimization problem:

$$
\begin{array}{r}
\max _{\left\{\mathbf{c}^{m}, \mathbf{c}^{f}\right\}} U^{f}\left(\mathbf{c}^{f}, \overline{\mathbf{k}} ; \mathbf{d}, \epsilon\right)+\mu(\mathbf{z}) U^{m}\left(\mathbf{c}^{m}, \overline{\mathbf{k}} ; \mathbf{d}, \epsilon\right) \\
\text { such that } \mathbf{c}^{m}+\mathbf{c}^{f}=\overline{\mathbf{c}},
\end{array}
$$

where $\mu(\mathbf{z})$ is the (relative) Pareto weight summarizing the (relative) individual decision power of the mother. This Pareto weight depends on so-called distribution factors $\mathbf{z}$ that affect the household decision process but do not directly impact the individual preferences or the budget constraint. The resulting demand equation for a generic (private) good $j$ then takes the following form:

$$
\theta_{j}(\overline{\mathbf{c}}, \mathbf{z} ; \mathbf{d}, \epsilon)=\xi_{j}(\overline{\mathbf{c}}, \mu(\mathbf{z}) ; \mathbf{d}, \epsilon) .
$$

The important difference with standard demand analysis is the presence of the Pareto weight function $\mu^{i}(\mathbf{z})$ and its functional dependence on distribution factors $\mathbf{z}$. If one can find variables $\mathbf{z}$ that affect only $\mu^{i}$ and not preferences-in other words, if the variables in $\mathbf{z}$ are not part of $\mathbf{d}$ - then these distribution factors can be used to test Pareto efficiency, the main underlying assumption of collective models.

Bourguignon, Browning, and Chiappori (2009) derive necessary and sufficient conditions for collective rationality that are valid for any type of good, either private or public. In order to understand the theoretical restriction that we want to test, we have to introduce the concept of $z$-conditional demand functions. Consider the demand for good $j$ resulting from program (2), $\theta_{j}=$ $\xi_{j}(\overline{\mathbf{c}}, \mu(\mathbf{z}) ; \mathbf{d}, \epsilon)$, where some of the elements of $\mathbf{z}$ may not be observed but at least one is. In particular, assume that there is at least one good $j$ and one observable distribution factor $z_{1}$ such that $\theta_{j}(\overline{\mathbf{c}}, \mathbf{z} ; \mathbf{d}, \epsilon)$ is strictly monotone in $z_{1}$. Given strict monotonicity, the demand function for good $j$ can be inverted on this factor: $z_{1}=\zeta\left(\overline{\mathbf{c}}, \mathbf{z}_{-1}, \theta_{j} ; \mathbf{d}, \epsilon\right)$. We can now define the following.

\footnotetext{
${ }^{5}$ We also refer to this paper for a further discussion of this assumption in the present context of targeted cash transfer programs.
} 
Definition 1 . The demand function for any good $l$ is a $z$-conditional demand if

$$
\begin{aligned}
\theta_{l} & =\theta_{l}\left(\overline{\mathbf{c}}, \mathbf{z}_{-1}, z_{1} ; \mathbf{d}, \epsilon\right)=\theta_{l}\left(\overline{\mathbf{c}}, \mathbf{z}_{-1}, \zeta\left(\overline{\mathbf{c}}, \mathbf{z}_{-1}, \theta_{j} ; \mathbf{d}, \epsilon\right) ; \mathbf{d}, \epsilon\right) \\
& =\varphi_{l}\left(\overline{\mathbf{c}}, \mathbf{z}_{-1}, \theta_{j} ; \mathbf{d}, \epsilon\right) .
\end{aligned}
$$

In other words, the demand for good $l$ can be written as a function of expenditure $\overline{\mathbf{c}}$, all distribution factors but the first, $\mathbf{z}_{-1}$, and the quantity demanded for good $j$. Although conditional demands are often used in demand analysis, it is useful to refer to it as $z$-demands because it incorporates the idea that distribution factors play a central role in the intrahousehold allocation stage of collective models. Empirically, the restriction that involves the $z$ conditional demand says that if there exists a distribution factor such that

$$
\frac{\partial \theta_{j}}{\partial z_{1}} \neq 0, \forall j
$$

then the demand for good $l$ is compatible with collective rationality if and only if there exists at least one good $j$ such that

$$
\frac{\partial \varphi_{l}\left(\overline{\mathbf{c}}, \mathbf{z}_{-1}, \theta_{j} ; \mathbf{d}, \epsilon\right)}{\partial z_{p}}=0 \quad \forall j \neq l \text { and } p=2, \ldots, s .
$$

The meaning of this testable restriction is the following. If we invert the demand for good $j$ on a distribution factor $z_{1}$, which is also significant for any other $\operatorname{good} l \neq j$, and we replace this demand into the demand of any other good $l \neq j$, the effect of any second distribution factor $z_{p}$ is going to be irrelevant. The intuition is that, by definition, distribution factors affect demand only through their effect on the location of the final outcome on the Pareto frontier. That is, they do not shift the Pareto frontier because they do not impact the individual preferences or the budget constraint. This implies that the effect of the bargaining weight is one-dimensional. Once the location on the Pareto set has been changed by the effect of the first distribution factor, the information brought by any other additional distribution factor is therefore uninformative. ${ }^{6}$

\section{Empirical Implementation}

We investigate how households respond to monetary incentives using a sample drawn from the surveys collected to evaluate the impact of PROGRESA. This is a CCT program implemented in rural Mexico in the late 1990s. The choice of

\footnotetext{
${ }^{6}$ Note that in proposition 2, Bourguignon, Browning, and Chiappori (2009) provide three equivalent necessary and sufficient conditions for collective rationality. Empirically, the condition that we use, involving $z$-conditional demands, is the most powerful, because single-equation methods are more robust than tests of the equality of parameters across equations.
} 
this data set is motivated by a variety of reasons. First, the monetary incentives were quite large and had a real effect on households by inducing them to change their consumption patterns. Second, the surveys are very detailed and of high quality, allowing us to construct vectors of quantity and prices for various important commodities. Third, the available data set contains two variables that have been shown in the literature to impact the decision process. We will investigate whether they can be considered as distribution factors by using them to test the main hypothesis outlined in the theory section.

The remainder of this section is divided into three subsections. First, we provide some background information on the program, presenting the evaluation surveys, how prices and quantities are aggregated, and some descriptive statistics of the sample used in our empirical analysis. Second, we discuss the consumption behavior of our sample - that is, household preferences and the observed demand equations - and outline the $z$-conditional demand system that we are going to estimate. The final subsection deals with the estimation strategy and the methodological issues that have been raised in the literature when one aims to identify the relationship of interest with data coming from a cash transfer program such as PROGRESA (e.g., Attanasio and Lechene 2002, 2014; Attanasio et al. 2013). In our context, we are particularly concerned with the endogeneity of both total expenditure and the number of children enrolled in secondary school.

\section{A. Program Design, Sample Selection, and Descriptive Statistics}

The original PROGRESA program was implemented between April 1998 and December 2000. Later it was extended to include new households both in rural and urban areas. From its start, PROGRESA was subject to rigorous evaluation based on random assignment. Ten thousand villages were included in the first expansion phase, of which 506 were selected in the evaluation sample: 320 of these were randomly chosen to have an early start of the program, and the remaining 186 formed the control group. In practice, households in these latter villages were not included in the program until late 1999, which means that they became eligible for the grant only after this date. Eligible households in treatment villages started receiving the cash transfers subject to the appropriate conditionality already in April 1998. Although eligible households in control villages were still observed during this time, they started benefiting from the payment (in the same manner) only after November 1999.

The main objectives of the program were to introduce incentives to improve the accumulation of human capital of children and, at the same time, to alleviate short-term poverty. To be eligible, a household must be sufficiently poor (in the program sense). The transfers were paid to the mother every 2 months and were 
largely in the form of scholarships to four grades of primary school, except the first two and the initial three grades of secondary school. These transfers are conditional on certain behavior: first, children must attend at least $85 \%$ of classes; second, household members must undergo periodic health checks; and third, the transfer recipients must attend nutrition and health classes. The strong involvement of the mother in the program was motivated by the assumption that mothers have stronger preferences for child well-being and are more responsible for managing household resources. Moreover, a change in relative income of spouses was motivated by the desire to change the position of women within rural families in Mexico, which was the intended by-product of the intervention. ${ }^{7}$

In the present paper, we use two postintervention surveys, in October 1998 and June 1999, which were collected 6 months and 12 months, respectively, after the households started receiving the cash transfers. The surveys include detailed information on expenditures at the household level and detailed information on members of the household. In order to have a homogeneous sample on which to test the hypothesis of interest, we use a subsample that satisfies the following restrictions. First, there are only households with both natural parents and between one and six children in our sample. This means that households with at least one other adult member are excluded, and the mother is always the recipient of the cash transfers. Second, households with children aged 17 or above are also excluded from the sample, in order to exclude households with multiple decision makers besides the parents. The resulting sample consists of 5,125 households observed in 1998 and 4,932 households observed in 1999. In the appendix (available online), we present the means of various householdlevel characteristics for our households in treatment and control villages in both waves. As we can see from the tables, households are disadvantaged in a number of important ways. First, the education of the head and the spouse is quite low, as the average adult has only slightly more than a primary school diploma. Second, families are quite large, as the average number of children is slightly below four. Third, almost $40 \%$ of the households have an indigenous origin. Finally, only a quarter of the villages have a secondary school.

We are interested in studying the household responses to cash transfers in terms of demand for different types of food, which, in our sample, represents

\footnotetext{
${ }^{7}$ The program was such a success that later it was expanded to other households in rural areas who were followed throughout the 2000 s as well as to households in urban areas. Other countries, including some developed nations, in Latin America, Asia, and Africa also adopted this kind of cash transfer program. PROGRESA has been found to increase education attainment (Schultz 2004; Attanasio et al. 2013), to decrease short-term poverty (Tommasi and Wolf 2016; Tommasi 2017), and to improve health (Gertler 2004; Behrman and Parker 2011). Detailed information on the program and its evaluations can be found in Skoufias (2005) and Fiszbein, Schady, and Ferreira (2009).
} 
about $80 \%$ of nondurable expenditure. ${ }^{8}$ The demand for it is modeled assuming separability of these goods from nonfood consumption and labor supply. The PROGRESA data contain very detailed information on both expenditure and consumption for many (narrowly defined) commodities. Following Attanasio and Lechene (2014), we use aggregated data to create budget shares of five different commodities: starches; pulses; fruit and vegetables; meat, fish and dairy; and other foods. As explained in detail by these authors, for each of the individual commodities that compose the five commodities that we use, consumption is computed to include what has been bought as well as quantities obtained from own production, payments in kind, and gifts. ${ }^{9}$ The quantities are valued in pesos using village-level price information derived from unit values. Home-produced consumption is also valued using local village-level unit values computed using information on purchases of the same commodities. ${ }^{10}$

We compute unit values of the five commodities that allow us to estimate the demand system. These are used to evaluate consumption in kind and to compute price indexes for each of the composite commodities. Unit values are computed for each household dividing the value of the purchase by its quantity. The value of the purchased commodity is computed by using village-level prices for individual commodities, where the village-level price is selected by looking at median unit value of the households that purchased that product in a given village. More details on the computation of these unit values and how price indexes are constructed can be found in Attanasio et al. (2013). This resulted in considerable variation in prices across villages and time in the data, which in turn allows us to get precise parameter estimates of the demand system.

\section{B. Functional Forms}

In our empirical application, we assume that households have preferences given by the integrable QAIDS demand system of Banks, Blundell, and Lewbel (1997). QAIDS allows flexible price responses, and the quadratic income allows the Engel curves to display a great variety of shapes. The indirect utility function of each household is assumed to be of the following form:

\footnotetext{
${ }^{8}$ We focus on demand for food for a variety of reasons. First and foremost, food consumption is the most important commodity in the budget of the expenditure of the households in the sample. Second, prices for nonfood consumption were not observed, making it practically impossible to use nonfood goods.

${ }^{9}$ Notice that, although in principle it is important to control for consumption of home-produced goods, only $6 \%$ of consumption is actually home produced.

${ }^{10}$ Since very few households in the sample engage in either food consumption outside the home or food consumption inside the home by nonhousehold members, we control for this in the empirical analysis by correcting for their direct effect on the budget.
} 


$$
V=\left\{\left[\frac{\ln x-\ln a(\mathbf{p})}{b(\mathbf{p})}\right]^{-1}+\lambda(\mathbf{p})\right\}^{-1},
$$

where

$$
\begin{aligned}
\ln a(\mathbf{p}) & =\alpha_{0}+\sum_{j=1}^{n} \alpha_{j} \ln p_{j}+\frac{1}{2} \sum_{j=1}^{n} \sum_{l=1}^{n} \gamma_{j l} \ln p_{j} \ln p_{l}, \\
b(\mathbf{p}) & =\prod_{j=1}^{n} p_{j}^{\beta_{j}} \\
\lambda(\mathbf{p}) & =\sum_{j=1}^{n} \lambda_{j} \ln p_{j} .
\end{aligned}
$$

The parameters $\alpha_{j}, \beta_{j}, \lambda_{j}$, and $\gamma_{j l}(\forall j, l)$ are to be estimated. Adding up requires that $\Sigma_{j} \alpha_{j}=1, \Sigma_{j} \beta_{j}=0, \Sigma_{j} \lambda_{j}=0$, and $\sum_{j} \gamma_{j l}=0$ (for all $l$ ). Homogeneity is satisfied if $\Sigma_{l} \gamma_{j l}=0$ (for all $j$ ). ${ }^{11}$

Applying Roy's identity to equation (7), we obtain the QAIDS budget share equations for each household and commodity $j$

$$
\begin{aligned}
w_{j}=\frac{\theta_{j}}{x}= & \alpha_{0}+\phi^{\prime} \mathbf{d}+\psi^{\prime} \mathbf{z}+\sum_{l=1}^{j} \gamma_{i l} \ln p_{l} \\
& +\beta_{j} \ln \left\{\frac{x}{a(\mathbf{p})}\right\}+\frac{\lambda_{j}}{b(\mathbf{p})}\left[\ln \left\{\frac{x}{a(\mathbf{p})}\right\}\right]^{2}+\epsilon_{j},
\end{aligned}
$$

where $w_{j}$ indicates the $j$ th budget share of a household facing a price vector $\mathbf{p}$ and total expenditure level $x$, whereas $\mathbf{d}$ and $\mathbf{z}$ are vectors of, respectively, individual demographic characteristics and distribution factors. The impact of these variables runs through the coefficients $\varphi$ and $\psi$, whose estimates constitute the main purpose of our empirical investigation. In principle, both vectors $\mathbf{d}$ and $\mathbf{z}$ could of course affect the demand system in other ways, not necessarily through the intercept only. As a robustness check, we reestimated the parameters of a general QAIDS model where demographic characteristics and distribution factors were allowed to change the curvature of the demand system in multiple ways. Almost all the additional parameters were not significant and did not impact the significancy of the intercept, which indicates that it is not restrictive to focus only on changes in the intercept.

\footnotetext{
${ }^{11}$ As shown by Browning and Chiappori (1998), Slutsky symmetry no longer needs to hold, so we did not have to impose this. It would be satisfied if $\gamma_{j l}=\gamma_{l j}(\forall j, l)$.
} 
In order to estimate the $z$-conditional demand for the budget share $w_{j}$, we have to allow that the conditioning share $w_{l}$ might be endogenous. This problem can be avoided because the excluded distribution factor on which the demand is inverted becomes a natural instrument for $w_{l}$. Let $N$, the relative family network, be the excluded distribution factor. The share for commodity $l(l=1, \ldots, n)$ can be inverted on this factor:

$$
N=\frac{1}{\psi_{N}} w_{l}-\frac{\psi^{\prime}}{\psi_{N}} \mathbf{z}_{-1}-\frac{1}{\psi_{N}} f_{l}(x, \mathbf{p})-\frac{\phi^{\prime}}{\psi_{N}} \mathbf{d}-\frac{1}{\psi_{N}} \epsilon_{l},
$$

where now $\mathbf{z}_{-1}$ contains only the remaining distribution factor and, for notational simplicity, $f_{l}(x, \mathbf{p})=\sum_{j=1}^{n} \gamma_{l j} \ln p_{j}+\beta_{l} \ln \{x / a(\mathbf{p})\}+\left[\lambda_{l} / b(\mathbf{p})\right][\ln \{x /$ $a(\mathbf{p})\}]^{2}$ for each good $l$. Substituting this equation for $N$ in the share for all other goods results in the system of $z$-conditional demand functions:

$$
w_{j}=\tilde{\alpha}^{\prime} \mathbf{z}_{-1}+\tilde{\gamma} w_{l}+\tilde{\beta} f(x, \mathbf{p})+\tilde{\phi}^{\prime} \mathbf{d}+\tilde{u}_{j}
$$

for all goods $j \neq l$. The test of collective rationality then boils down to a test of the significance of $\tilde{\alpha}$.

\section{Endogeneity}

Since our data set comes from the evaluation of a cash transfer program, which has some important conditionality attached, the main methodological concern in estimating the demand system (9) is the endogeneity of total expenditure and child school enrollment. A further methodological concern is the nonlinearity of the system, which makes the recovery of the parameter estimates more complicated. The latter issue is tackled by estimating the complete system with the iterated feasible generalized nonlinear least squares (FGNLS) estimator. The former concern is tackled with a control function approach, as it is commonly applied in demand analysis (e.g., Blundell and Robin 1999), where the residuals, estimated in the first stage, enter as a polynomial of second order. In the following paragraphs, we explain the concern for each of the endogenous variables and how we deal with it.

For the endogeneity of total expenditure, notice that the implicit assumption behind our exercise is the idea that households decide their budget structure under two-stage budgeting: first, they decide how much to allocate to food and then how much to allocate to each of the five components of food. The residuals in (9) can be interpreted as the household's unobserved tastes that affect each budget share. There are two main arguments in the literature for why total expenditure $x$ should be endogenous. One is that taste shocks that determine total expenditure $x$ may be correlated with the unobserved shocks to a particular food 
component in the system. The other is that measurement error in the budget shares may be correlated with measurement error in total expenditure. In the present paper, we follow Attanasio and Lechene $(2002,2014)$ and instrument total expenditure $x$ with the average agricultural wage in the village. This is a strong instrument, and the implicit assumption in using it is that any measurement error in village-level income is not correlated with measurement error of household total expenditure, which is an assumption commonly used in the literature. As Attanasio and Lechene $(2002,2014)$ explain at length, this is a valid instrument if labor supply is separable from consumption. With respect to this, there is significant evidence that PROGRESA did not affect adult labor supply, and hence it is not a concern for us (e.g., Skoufias 2005).

The second endogenous variable in system (9) is the number of children enrolled in school. As we explained before, eligible households receive a (large) portion of the grant if their children are enrolled and attend school. This conditionality requirement, which is controlled for in the demand equations, might affect consumption behavior if sending children to school imposes additional costs such as books, uniforms, and so on. Moreover, if children are fed in school, this would further impact the budget share of food. Enrollment in primary school is almost universal in rural Mexico and hence not affected by the grant. In order to allow for endogeneity of children in secondary school, we follow Attanasio and Lechene $(2002,2014)$ and instrument it with a dummy variable indicating the existence of a secondary school in the village and with the distance from the closest secondary school if no such school is present in the village. The implicit assumption made is that these two instrumental variables affect the schooling decisions of parents but not directly the structure of their expenditure on food.

Finally, before concluding this section, it is worth noting that the QAIDS budget share equations of the $z$-conditional demand depicted in equation (10) contain a third endogenous variable: the budget share of the conditioning good. As the conditioning good $\theta_{l}$ is correlated with the unobserved taste shock of the demand for good $\theta_{k}$, this needs to be instrumented for. The natural instrument to use is already suggested by theory and by the $z$-conditional demand test that we run: the distribution factor used to invert the demand of the conditioning good satisfies the common requirements for valid instrumental variables. Hence, in estimating equation (10), we apply the same control function approach as before, adding the residuals from the first stage of the conditioning good as well.

\section{Potential Distribution Factors}

In the present paper, we want to investigate whether eligibility for PROGRESA is only impacting the intrahousehold decision process or whether there is also 
evidence that it is impacting other channels. To perform this empirical exercise, we need to find at least two variables that affect the allocation of resources but potentially not the preferences. These variables are called distribution factors and enter the Pareto weight function of the two agents within the household. Browning, Chiappori, and Weiss (2014) report the most commonly used distribution factors in the literature. As these authors argue, it is a difficult exercise to find plausible distribution factors because theory does not give guidance as to what constitutes a distribution factor.

Our first and most important potential distribution factor is eligibility for PROGRESA. This is a dummy variable taking a value of 1 if the household belongs to a treated village and 0 otherwise. Since the grant is targeted to the mother, receiving the transfers constitutes an exogenous increase in the share of the household income that she controls. This share of income is not an argument of preferences, and conditional on total resources available, it does not affect the budget constraint. Given the random assignment of the program, the treatment variable constitutes in principle an ideal distribution factor, which explains its popularity in the recent literature to test the collective model.

Note that the grant affects not only the distribution of resources within the household but also the total resources available. This implies that we need an appropriate specification of the demand system to control for total resources available after the treatment. Conditional on all the resources, including those coming from the program, receiving the PROGRESA transfer should make no difference to the allocation of household resources among different commodities. If instead, after conditioning, the grant has a residual effect on allocation, it must be because it has shifted the demand as a consequence of a shift in the $\mathrm{Pa}$ reto weights.

As a second distribution factor, we use the relative importance of the husband and wife's family network in the village. This information was collected by Angelucci et al. (2009) and used as a distribution factor to test the collective model by Attanasio and Lechene (2014). The main idea behind the use of the network information is the fact that a stronger presence of family members in the village affects the individual value of their outside option. Indeed, as these authors argue, it is possible that the relative weights of husband and wife in the allocation of resources depend, within the context of poor marginalized rural households, on the relative strength and influence of the two extended families in the village. The relative importance of the spouse's networks is constructed by Angelucci et al. (2009) as follows. The authors exploit the fact that the PROGRESA evaluation surveys are a census of each village and the convention of Spanish last names to map the network of relatives within each community. Indeed, in Spanish-speaking countries, individuals get two surnames, the first 
from the father and the second from the mother. Using the PROGRESA surveys, it is possible to know the number of relatives, for each adult, that are present in the village. The relative importance of the husband and wife's networks is then constructed in two ways: the size and wealth of the networks. ${ }^{12}$

At this point, one may be worried that, in the presence of altruism, if an adult member cares about their siblings, presumably their siblings care about them. Hence, one could argue that if this adult has a relatively large family network, social norms may induce him or her to behave in a way that is closer to the preferences of the network. In other words, the number of siblings might affect preferences rather than bargaining. However, under the assumption that both adult members live under the same set of social norms, the construction of the distribution factor as a ratio of the two adults' network, would net away this concern. Next, concerning the effect on budget, the main reason why one could argue that the number of siblings in the village might have a direct effect on the demand for food is that, in rural Mexico, it is common practice for siblings to share meals. Although this fact would not invalidate that relative family network does not affect the budget, it does imply that if we do not account for the direct effect of the number of siblings on the demand for food, we might obtain biased estimates. Our empirical implementation avoids this potential bias because we indeed control for the number of relatives who share meals with the household as a determinant of expenditure shares.

Finally, we want to make two important remarks about our empirical implementation of the BBC test based on $z$-demands. First, the choice of the conditioning distribution factor and the conditioning good is crucial for the reliability of the empirical results. Theory indicates that the conditioning distribution factors must be statistically relevant and must affect the conditioning good monotonically. ${ }^{13}$ In the empirical analysis, we use the network variable as our preferred conditioning distribution factor, which satisfies all the requirements of the theory and is statistically significant in our own empirical exercise. Second, part of the discussion in the collective model literature is the nature and

\footnotetext{
${ }^{12}$ More formally, for each individual $i=m, f$, they construct the relative size of the networks as the ratio of $n_{i} / n_{m}+n_{f}$, where $n_{i}$ is either the number of relatives in the village or the value of their wealth for each individual $i$. Wealth is proxied by (food) consumption of the individual's relatives. ${ }^{13}$ Historically, very few papers have rejected the collective model. This under-rejection of the effciency hypothesis has been recently criticized by Dauphin, Fortin, and Lacroix (2018). In relation to the $z$-conditional test, they argue that if we apply Bourguignon, Browning, and Chiappori (2009) strictly, the test requires that at least one distribution factor (locally) affects all demand equations. However, this assumption is hardly ever satisfied empirically, which means that test results are often based on the estimate of a parameter that is obtained by dividing two numbers that are very small. Therefore, our test results are based on parameters attached to distribution factors that are both relevant for the household demand of both years.
} 
validity of the distribution factors used, whether discrete or continuous. We point out that, for the reliability of the results, it is important that the second distribution factor (the one on which the demand system is inverted) is continuous. This is the case in our empirical exercise for our network variable. ${ }^{14}$

\section{Results and Discussion}

In this section, we first present the results of the BBC test of the collective model and show that, contrary to the existing literature, it is not rejected at the beginning of the program (first wave, 6 months after the start of the program), but it is rejected later in time (second wave, 12 months after the start of the program). Second, we discuss several possible explanations for these findings and provide suggestive evidence that one could interpret these results as an indication that the PROGRESA treatment may not only impact the decision process but also change individual preferences.

In all specifications, we instrument total food expenditure with the villagelevel agricultural wage (and its square) and the number of children in secondary school with a dummy if there is a secondary school present in the village or the distance to the closest secondary school. We also control for a large set of pretreatment village, household, and individual characteristics. Village characteristics include the town size and prices. Household characteristics include the number of young children, the number of children enrolled in primary school, the number of children enrolled in secondary school, the number of relatives eating in the household, and the number of household members eating outside the household. Individual characteristics include the level of education of both parents, the age of the household head, and an indigenous head dummy. All the standard errors are clustered at the village level and bootstrapped 300 times.

\section{A. Results of the BBC Test}

We first estimate the unconditional (QAIDS) demand system for various (sub)groups in our sample: respectively, the full sample, the subgroups defined by splitting the sample according to the 2 years in our data set, and subgroups for each year based on different education and age differences between spouses. We report only the results for the tests on the two cross-sections separately, because these are the only ones where there are at least two demand equations with two significant effects of the distribution factors. In all other subgroups that we have defined, the effects of the distribution factors are always too weak

\footnotetext{
${ }^{14}$ Note that using the concept of equivalent transfers (i.e., transfers of nonlabor income), Kapan (2010) shows that the identification results based on distribution factors are still valid if the distribution factor is discrete.
} 
to provide reliable estimates of the $z$-conditional demand test, and hence no clear pattern was found.

The main parameters of interest are reported in table 1 . The estimated demand system is able to predict very well the observed budget allocation for both control and treatment groups in both periods, as reported in the appendix. Using these demand equations, we investigate whether the collective model is able to rationalize the observed budget allocation. In order to do so, we estimate $z$ conditional QAIDS demands by taking pairwise combinations of the demand equations that are responsive to the distribution factors. As we can see, these are starches; fruits and vegetables; and meat, fish, and dairy products for the 1998 observation. Whereas for 1999, these are starches; pulses; fruits and vegetables;

TABLE 1

UNCONDITIONAL (QAIDS) DEMAND SYSTEM

\begin{tabular}{|c|c|c|c|c|c|}
\hline & Starches & Pulses & $\begin{array}{l}\text { Fruits and } \\
\text { Vegetables }\end{array}$ & $\begin{array}{c}\text { Meat, Fish, } \\
\text { and Dairy }\end{array}$ & $\begin{array}{l}\text { Other } \\
\text { Foods }\end{array}$ \\
\hline & \multicolumn{5}{|c|}{ A. October 1998, 6 Months after the First Transfer } \\
\hline Treatment & $\begin{array}{l}.020^{\star \star} \\
(.009)\end{array}$ & $\begin{array}{c}.004 \\
(.006)\end{array}$ & $\begin{array}{c}-.012^{\star \star} \\
(.005)\end{array}$ & $\begin{array}{c}-.016^{\star *} \\
(.008)\end{array}$ & $\begin{array}{c}.004 \\
(.003)\end{array}$ \\
\hline Network & $\begin{array}{c}-.013^{\star} \\
(.007)\end{array}$ & $\begin{array}{r}-.005 \\
(.004)\end{array}$ & $\begin{array}{l}.011^{\star \star *} \\
(.004)\end{array}$ & $\begin{array}{l}.013^{\star \star} \\
(.005)\end{array}$ & $\begin{array}{r}-.006 \\
(.004)\end{array}$ \\
\hline $\begin{array}{l}\text { Joint test: } \\
\text { Treatment } \\
\text { Network }\end{array}$ & $\begin{array}{l}10.24(p= \\
18.54(p=\end{array}$ & $\begin{array}{l}.04) \\
.00)\end{array}$ & & & \\
\hline Network & \multicolumn{5}{|c|}{ B. June 1999, 12 Months after the First Transfer } \\
\hline Treatment & $\begin{array}{c}-.049^{* \star \star} \\
(.007)\end{array}$ & $\begin{array}{c}-.021^{\star *} \\
(.010)\end{array}$ & $\begin{array}{l}.021^{\star \star \star} \\
(.005)\end{array}$ & $\begin{array}{c}.007 \\
(.006)\end{array}$ & $\begin{array}{l}.041^{\star \star \star} \\
(.003)\end{array}$ \\
\hline Network & $\begin{array}{l}.013^{\star \star} \\
(.007)\end{array}$ & $\begin{array}{c}.003 \\
(.003)\end{array}$ & $\begin{array}{r}-.000 \\
(.003)\end{array}$ & $\begin{array}{c}-.002 \\
(.005)\end{array}$ & $\begin{array}{c}-.013^{\star \star \star} \\
(.004)\end{array}$ \\
\hline \multicolumn{6}{|l|}{ Joint test: } \\
\hline Treatment & $88.55(p=$ & .00) & & & \\
\hline Network & $13.16(p=$ & 01) & & & \\
\hline
\end{tabular}

Notes. We report only the parameter estimates (and standard deviation) of the main distribution factors. Network refers to the relative family network of the wife. The sample size in the two waves is 5,125 and 4,932 observations, respectively. In all specifications, we instrument total food expenditure with the village-level agricultural wage (and its square) and the number of children in secondary school with a dummy if there is a secondary school present in the village and the distance to the closest secondary school. We control for a large set of pretreatment village, household, and individual characteristics. Village characteristics include the town size and prices. Household characteristics include the number of young children, the number of children enrolled in primary school, the number of children enrolled in secondary school, the number of relatives eating in the household, and the number of household members eating outside the household. Individual characteristics include the education of both parents, the age of the household head, and an indigenous head dummy. All the standard errors are clustered at the village level and bootstrapped 300 times. Under joint tests of each distribution factor, we report the $\chi^{2}$ statistic and $p$-values for the tests.

* $p<.10$.

$\star * \quad p<.05$.

$\star \star \star * \quad p<.01$ 
and other foods. Hence, this means that in 1998, we first use fruits and vegetables as conditioning good, invert it on network, and run the BBC test on the remaining goods where the treatment variable is significant. ${ }^{15}$ Then we use meat, fish, and dairy products to invert the system and test the model on the remaining goods and so on for the remaining goods in 1998 and 1999. For completeness of the results, we report the estimates of all goods where at least one distribution factor is significant, but one should keep in mind that the most powerful results come from specifications where both demand equations are responsive to both distribution factors. Hence our preferred specifications and test results are those in columns $1-4$ of table 2 . Note that these two goods represent $30 \%$ of the food budget in the first wave and 60\% in the second wave.

Table 2 shows that in 1998, 6 months after the first transfer, not only can we not reject the null hypothesis for all specifications but also the magnitude of the coefficients always goes down, often close to zero, as theory predicts. In light of the model outlined before, this implies that we find convincing empirical evidence in favor of the collective model. A different story emerges, however, when we look at the 1999 data, 12 months after the households started receiving the cash transfers. In this case, the null hypothesis can be rejected in three out of six specifications, and the magnitude of the $z$-conditional parameters never goes down to zero (as in the previous wave). ${ }^{16}$

As a robustness check, we attempted to estimate all the $z$-conditional QAIDS demands simultaneously and thereby performing a joint test of efficiency. However, due to the highly nonlinear and collinear nature of the system, this implementation was not feasible. As an alternative, we estimate a linearized version of the $z$-demand system. This procedure, although imperfect, allows us to estimate the covariances of the parameters attached to the treatment indicator across the system. By doing so, we obtain that all these parameters are in magnitude smaller than $10^{-4}$. Interpreting this result as evidence in favor of the assumption that the treatment parameters might be independent across the system, we can construct a joint test statistic. This simply boils down to the sum of the squared $t$-statistics, which can be calculated using the information reported in table 2 . The resulting $\chi^{2}$ statistic for the two most responsive equations is equal to 4.54 in the 1998 wave and 15.97 in the 1999 wave. Therefore, on the basis of this joint test and

\footnotetext{
${ }^{15}$ To verify whether demand is monotone within the family network, which we need to be able to invert, we added the squared value of this variable to our demand equations. These extra parameters turned out to be not statistically significant.

${ }^{16}$ Note that there is potentially a concern with weak instruments. Even though instrument strength is not that different from that used in similar papers in the literature (i.e., our $\chi^{2}$ statistics range from 13 to 28), it is also true that it is borderline in most specifications. See the appendix tables for more details.
} 
TABLE 2

Z-CONDITIONAL DEMAND (BBC) TEST

\begin{tabular}{|c|c|c|c|c|c|c|c|c|c|c|c|c|}
\hline & (1) & (2) & (3) & (4) & (5) & (6) & (7) & (8) & (9) & (10) & (11) & (12) \\
\hline & QAIDS & z-Conditional & QAIDS & z-Conditional & QAIDS & $z$-Conditional & QAIDS & $z$-Conditional & QAIDS & z-Conditional & QAIDS & $z$-Conditional \\
\hline & \multicolumn{12}{|c|}{ A. October 1998, 6 Months after the First Transfer } \\
\hline & \multicolumn{2}{|c|}{$\begin{array}{l}\text { Meat, Fish, } \\
\text { and Dairy }\end{array}$} & \multicolumn{2}{|c|}{$\begin{array}{c}\text { Fruits } \\
\text { and Vegetables }\end{array}$} & \multicolumn{2}{|c|}{ Starches } & \multicolumn{2}{|c|}{ Starches } & \multicolumn{2}{|c|}{$\begin{array}{l}\text { Meat, Fish, } \\
\text { and Dairy }\end{array}$} & \multicolumn{2}{|c|}{$\begin{array}{c}\text { Fruits } \\
\text { and Vegetables }\end{array}$} \\
\hline \multirow[t]{2}{*}{ Treatment } & $\begin{array}{l}-.016^{\star \star} \\
(.008)\end{array}$ & $\begin{array}{l}.007 \\
(.010)\end{array}$ & $\begin{array}{c}-.012^{\star \star} \\
(.005)\end{array}$ & $\begin{array}{c}-.002 \\
(.006)\end{array}$ & $\begin{array}{l}.020^{\star *} \\
(.009)\end{array}$ & $\begin{array}{c}.011 \\
(.013)\end{array}$ & $\begin{array}{l}.020^{\star *} \\
(.009)\end{array}$ & $\begin{array}{l}.006 \\
(.010)\end{array}$ & $\begin{array}{c}-.016^{\star \star} \\
(.008)\end{array}$ & $\begin{array}{r}-.003 \\
(.010)\end{array}$ & $\begin{array}{c}-.012^{\star \star} \\
(.005)\end{array}$ & $\begin{array}{l}.010 \\
(.006)\end{array}$ \\
\hline & \multicolumn{4}{|c|}{ Both df significant at $p \leq .10$} & \multicolumn{8}{|c|}{ At least one df significant at $p \leq .10$} \\
\hline $\begin{array}{l}\text { Conditioning good } \\
\text { p-value treatment } \\
\text { Joint test: } \\
\text { All equations } \\
\text { Most responsive equation }\end{array}$ & \multicolumn{2}{|c|}{$\begin{array}{l}\text { Fruits and vegetables } \\
\qquad .46\end{array}$} & \multicolumn{2}{|c|}{$\begin{array}{c}\text { Meat, fish, and dairy } \\
.78\end{array}$} & \multicolumn{2}{|c|}{$\begin{array}{l}\text { Fruits and vegetables } \\
\qquad .41\end{array}$} & \multicolumn{2}{|c|}{$\begin{array}{c}\text { Meat, fish, and dairy } \\
.51\end{array}$} & & $\begin{array}{l}\text { arches } \\
.76\end{array}$ & & $\begin{array}{l}\text { tarches } \\
.11\end{array}$ \\
\hline \multirow{2}{*}{ Most responsive equation } & \multicolumn{12}{|c|}{ B. June 1999, 12 Months after the First Transfer } \\
\hline & \multicolumn{2}{|c|}{ Starches } & \multicolumn{2}{|c|}{ Other Foods } & \multicolumn{2}{|c|}{ Starches } & Fruits an & nd Vegetables & \multicolumn{2}{|c|}{ Starches } & \multicolumn{2}{|c|}{ Other Foods } \\
\hline \multirow[t]{2}{*}{ Treatment } & $\begin{array}{l}-.049^{\star \star \star} \\
(.005)\end{array}$ & $\begin{array}{l}-.042^{\star \star \star} \\
(.011)\end{array}$ & $\begin{array}{l}.041^{\star \star \star} \\
(.003)\end{array}$ & $\begin{array}{l}.026 \\
(.022)\end{array}$ & $\begin{array}{c}-.049^{\star \star \star} \\
(.005)\end{array}$ & $\begin{array}{r}-.034 \\
(.051)\end{array}$ & $\begin{array}{l}.021^{\star \star \star} \\
(.003)\end{array}$ & $\begin{array}{l}.041^{*} \\
(.022)\end{array}$ & $\begin{array}{c}-.049^{\star \star \star} \\
(.005)\end{array}$ & $\begin{array}{l}-.034^{\star \star \star} \\
(.010)\end{array}$ & $\begin{array}{l}.041^{\star \star \star} \\
(.003)\end{array}$ & $\begin{array}{c}.106 \\
(.149)\end{array}$ \\
\hline & \multicolumn{4}{|c|}{ Both df significant at $p \leq .10$} & \multicolumn{8}{|c|}{ At least one df significant at $p \leq .10$} \\
\hline $\begin{array}{l}\text { Conditioning good } \\
\text { p-value treatment } \\
\text { Joint test: }\end{array}$ & \multirow{2}{*}{\multicolumn{2}{|c|}{$\begin{array}{l}\text { Other foods } \\
\quad .00\end{array}$}} & \multirow{2}{*}{\multicolumn{2}{|c|}{$\begin{array}{l}\text { Starches } \\
.25\end{array}$}} & \multicolumn{2}{|c|}{$\begin{array}{l}\text { Fruits and vegetables } \\
\qquad .51\end{array}$} & \multicolumn{2}{|c|}{$\begin{array}{c}\text { Starches } \\
.06\end{array}$} & \multicolumn{2}{|c|}{$\begin{array}{l}\text { Pulses } \\
.00\end{array}$} & \multicolumn{2}{|c|}{$\begin{array}{c}\text { Fruits and vegetables } \\
.47\end{array}$} \\
\hline $\begin{array}{l}\text { All equations } \\
\text { Most responsive equation }\end{array}$ & & & & & & $\begin{aligned} \chi^{2}(6) & =32.16[ \\
\chi^{2}(2) & =15.97[\end{aligned}$ & $\begin{array}{l}p \text {-value }= \\
p \text {-value }=\end{array}$ & $\begin{array}{l}.00] \\
.00]\end{array}$ & & & & \\
\hline
\end{tabular}

Note. We use network as the conditioning distribution factor. We report only the parameter estimates (and standard deviation) of the treatment indicator. The sample size in the two waves is 5,125 and 4,932 observations, respectively. All regressions contain the same set of regressors as outlined in table 1 . All standard errors are clustered at the village level and bootstrapped 300 times.

${ }^{*} p<.10$

$\star * * 0.05$.

$\star * \star p<.01$ 
the maintained assumption, we cannot reject the null hypothesis of efficiency in 1998, whereas we can reject it for 1999. We reach the same conclusions when we use all six equations. Although this is not the ideal joint test of the flexible QAIDS, it is reassuring that, under the maintained assumption of independence across equations, we can confirm the results for both 1998 and 1999 .

These results are somewhat different from those of the recent literature (in particular, Bobonis 2009; Attanasio and Lechene 2014; and Angelucci and Garlick 2016). This can be explained by several reasons. First, our sample selection strategy and variables choice is slightly different. Our main — and most informative-results focus on the two waves separately, while all the other papers pool the waves. As our empirical results demonstrate, they fail as such to fully capture the heterogeneity over time. Next, similarly to Attanasio and Lechene (2014) but differently from Bobonis (2009) and Angelucci and Garlick (2016), we use only two waves of data after PROGRESA began to distribute cash transfers, and we focus on food consumption. The other authors use three waves and also model nonfood consumption. The problem with this implementation is that the surveys do not contain information on prices for nonfood commodities, and hence it is not possible to implement the QAIDS model that we specified above. Finally, again similarly to Attanasio and Lechene (2014) but differently from Bobonis (2009) and Angelucci and Garlick (2016), we use treatment and relative size of the wives' family network as distribution factors.

Besides these differences in the sample selection strategy and the variables choice, a second main difference is our implementation of the test of Pareto efficiency. As explained above, to implement the BBC test, one has to invert the demand equations. To obtain statistically reliable results, it is therefore crucial to have unbiased estimates and to focus on the most responsive demand equations. Therefore, our test is based on the parameters estimated from a fully fledged QAIDS model, whereas the other papers are based on a linear version of it, called $\ell$-QAIDS. Although the BBC test does not, in principle, require either price variation or the estimate of the parameters attached to prices, bypassing a proper estimation of the demand system may lead to biases in the parameter estimates. ${ }^{17}$ Next, with respect to inverting the demand functions, some of our sample selections resulted in very small (and often insignificant) estimates of the parameters. As a consequence, this makes the BBC test very unreliable, since (after the inversion) it is based on the ratio of two small numbers. This explains why we do not

\footnotetext{
${ }^{17}$ See, e.g., Pashardes (1993), Buse (1994, 1998), Moschini (1995), and Matsuda (2006) for more discussion on how biased estimates of a demand system may or may not influence the empirical conclusions. In the appendix, we argue more in detail why the BBC test is an example where these biases may be influential.
} 
obtain similar conclusions in term of cross-sectional heterogeneity to those of Angelucci and Garlick (2016).

As a final remark, one may be concerned that household composition (and hence sample composition) is changing through time in ways that might contribute to the change in efficiency through time. In particular, (i) some households may age out of the sample over time, (ii) transfer eligibility may induce some households to migrate (Stecklov et al. 2005; Angelucci 2015), or (iii) transfer eligibility may change separation and cohabitation behavior (Bobonis 2011). ${ }^{18}$ In the appendix, we provide several arguments in support of the claim that none of these issues is impacting our results.

\section{B. Interpreting These Results in Light of the Collective Model}

In principle, the rejection of the BBC test, and thus the collective model, in the second period leaves open a multitude of possible explanations. Part of these are related to the decision process of the household and the corresponding underlying assumptions (for some recent empirical discussion in the context of developing countries, see Baland and Ziparo 2018). First, it could be interpreted as an indication of noncooperative (or strategic) behavior, which in turn leads to suboptimal decisions. ${ }^{19}$ However, Chiappori and Naidoo (2020) show that distribution factors in a noncooperative model should satisfy the same testable implications as the ones we tested (in addition to some extrapartial differential equations), which excludes this explanation, and in our opinion, the same conclusion extends to the so-called semicooperative models introduced by d'Aspremont and Dos Santos Ferreira (2014) and Cherchye et al. (2020). ${ }^{20}$

Second, given that we study the heterogeneity of household behavior (in terms of compliance with the assumption of Pareto efficiency), over time, there is a possible need to extend our static framework to include intertemporal effects while maintaining the assumption of exogenous bargaining weights. This would

${ }^{18}$ We thank an anonymous reviewer for pointing out these potential issues.

${ }^{19}$ In this context, noncooperative behavior stands for household decisions that are a Nash equilibrium in a public good game with voluntary contributions of the household members. Cherchye, Demuynck, and De Rock (2011), Lechene and Preston (2011), and d'Aspremont and Dos Santos Ferreira (2014) present testable implications of this model on the basis of price-income variation, while Chiappori and Naidoo (2020) present them on the basis of distribution factors.

${ }^{20}$ Recently, Lewbel and Pendakur (2019) introduce the notion of conditional efficiency to indicate that noncooperative behavior could be linked to changes in the household technology driven by choices of one of the partners. These changes alter the utility possibility set, which in turn interferes with the demand for food. This alternative interpretation can therefore also explain our rejections of Pareto efficiency. To properly test for this, one needs to extend our basic model to allow for a household technology (see Browning, Chiappori, and Lewbel 2013) and to observe covariates related to endogenous changes in the household technology (e.g., increase in violence or alcohol consumption). 
allow us, for instance, to focus on commitment in household decisions, which could in turn lead to an ex post inefficient decision. As shown by Mazzocco (2007), the significance of our distribution factors indicate that there is only limited commitment. That is, due to changes in the distribution factors, participation constraints to stay inside the marriage become binding and trigger revisions in intrahousehold bargaining power. The rejection of the collective model could therefore be interpreted as an indication that households could not reach a new Pareto optimal outcome, implying that the spouses should divorce. In the appendix, we discuss in more detail that there is however too little divorce for our data at hand to explain our results.

Third, one may be concerned that our results depend on our specific structural model, which excludes, for instance, household production, endogenous bargaining weights, and imperfect information (see Basu 2006; Baland and Ziparo 2018; Walther 2018). This is, of course, a possible explanation and, relaxing some of the assumptions of the model, would in principle allow us to better grasp the mechanisms underlying the (potential) sources of (in)efficieny. Also, and in a similar vein, one may be concerned with our empirical strategy, which is based on the effects of two very specific distribution factors in a QAIDS model à la Banks, Blundell, and Lewbel (1997) and a limited data set. Having access to better data, including alternative distribution factors or measures of preference shocks, would in principle allow for better empirically investigating the heterogeneity in (in)efficiency across households. For instance, we could not explicitly investigate preference changes due to lack of data or pursue further analysis at different subgroup levels (see, e.g., Angelucci and Garlick 2016), since the effects of our distribution factors were always too weak to provide statistically reliable test results.

This being said, we can provide three related pieces of evidence, consistent with our collective model, suggesting that this rejection may indicate that the treatment is not only empowering women but also changing individual preferences. This new interpretation implies that the treatment variable can no longer be interpreted as a proper distribution factor (that only impacts the decision process), which in turn implies that the BBC test is no longer valid. In terms of our structural model presented in section II, this suggests that the treatment dummy is not yet a preference shifter in the first period (i.e., it is not part of the $\mathbf{d}$ variables), whereas it should be interpreted as a preference shifter in the second period.

First, and most importantly, as cited above, there is ample empirical evidence showing that the treatment has changed the composition of food expenditures significantly over time. Interestingly, Hoddinott and Skoufias (2004) find that approximately one and a half years after the installment of PROGRESA, there is a significant increase in caloric intake, whereas there seems to have been no significant effect in the first periods of treatment by PROGRESA. Importantly, 
they also show that the higher impact was found on the consumption of highly nutritious foods, such as fruits and vegetables, after controlling for income effects. The authors point to the training courses (platicas) of the PROGRESA program on health and nutrition issues as the main driving force for this dynamic effect. This is exactly in line with the results we present in tables 1 and 2 .

Second, and related to this substantial educational component, mothers receive intensive educational and programmatic meetings, with the aim to empower them on several dimensions (e.g., on the importance of good quality food but also on speaking up with respect to their rights vis-à-vis health-care providers). It could be that the impact of this training, which is a combination of more information and empowerment, may only take place gradually. In terms of our structural model, this means that mothers have a higher preference for expenditures on the public good, for example, children (see Barber and Gertler 2010), which explains the drastic change in food expenditures over time. Although this is only circumstantial evidence, it is in line with our results and those of Hoddinott and Skoufias (2004).

Finally, the June 1999 survey round of the PROGRESA data, the one that gives us the rejection of the collective model, contains a series of questions regarding aspirations and expectations of decision makers within the household. Attanasio and Lechene (2002) show that, after the implementation of the program, the answers to the decision-making questions are substantially different between the treatment and control groups. Most of these results are explained by the husbands in treatment villages making fewer decisions on their own. The magnitude of these differences is not very large but still statistically significant. Unfortunately, these questions pertaining to decision-making within the household were asked only in May 1999, so it is impossible to use them to test for dynamic effects in the change of intrahousehold decision-making. Notwithstanding this limitation, it does suggest at least that the PROGRESA program may have significantly affected the households' way of thinking about joint decisions and public goods. ${ }^{21}$

Summarizing through the lens of our model, although PROGRESA is, of course, likely to have an overall positive effect on the welfare of children and women in rural Mexico, empowering women might have changed the preferences of the spouses in different ways. In this respect, it also relevant to refer to the empirical findings on the incidence of violence and alcohol abuse among

\footnotetext{
${ }^{21}$ Unfortunately, our data, with the unique family network variable, do not contain the household IDs, which implies that we could not directly integrate this extra information in our empirical analysis. The same applies to explicitly linking households in both waves.
} 
spouses in the targeted households (e.g., Angelucci 2008; Bobonis, GonzálezBrenes, and Castro 2013; Bobonis, Castro, and Morales 2018). ${ }^{22}$ Not only does this formally exclude the underlying assumptions of the BBC test to verify the validity of the collective model, it is also intuitive that this may create frictions within the household that could lead to some second-order negative effects in terms of suboptimal household decisions. This implies that the observed budget allocation of food cannot be solely explained by an induced shift of bargaining power toward the mother but should be accompanied by (empirical) models that allow for changing preferences over time. Although our interpretations are rather suggestive, at the same time they indicate multiple interesting avenues for further research.

\section{Conclusion}

We structurally analyzed whether the collective model can rationalize the demand equations of food for a sample of households affected by the PROGRESA CCT program. This CCT program was implemented in rural Mexico in the late 1990 s and targeted poor families. The large monetary incentives had a substantial effect on households' behavior, inducing them to change their food consumption patterns. As shown by Attanasio and Lechene (2014), this change can be explained only by the impact of the CCT on the intrahousehold decision process.

In this paper, we further investigated this impact. Based on the test introduced by Bourguignon, Browning, and Chiappori (2009), we show that households are consistent with the collective model only in 1998, 6 months after the beginning of the program, but reject the test 12 months after the first cash transfer. We discuss several potential explanations for this rejection and provide suggestive arguments that our findings may indicate that the PROGRESA program is not only impacting the decision process but may also be changing individual preferences over time. This, in turn, is an indication of the invalidity of using the treatment variable as a proper distribution factor. The differences in our results with those of the existing literature demonstrate the need for using a fully flexible demand system in order to capture the impact of price variation. Moreover, our paper also shows that in order to obtain a powerful and reliable application of the $\mathrm{BBC}$ test of the collective model, it is crucial that both demand equations are responsive to both distribution factors.

\footnotetext{
${ }^{22}$ Angelucci (2008) notes that the likelihood to receive more violent threats is related to the size of the cash transfers received by the household. Similar arguments, albeit in different contexts from PROGRESA, have been put forward by Hidrobo and Fernald (2013) and Ramos (2017). Moreover, experimental evidence suggesting behavioral changes arising as a result of cash transfers has also been found in a recent paper by Almas et al. (2018).
} 
Furthermore, our results are suggestive of a need for new structural models, including intertemporal and/or noncooperative features, to capture the impact of so-called distribution factors and corresponding empirical evidence to analyze second-round effects of CCT programs such as PROGRESA. Alternatively, one could also fully integrate the marriage market in a structural model in order to circumvent the use of distribution factors (e.g., Cherchye et al. 2017). Related to our empirical findings, future policy intervention, such as CCT programs, could be complemented with a measurement of the preferences for public goods (e.g., children) of the parents both at the beginning of the intervention and after some time. This would allow for estimating explicitly their impact on the demand for private and public goods and disentangling changes in preferences from changes in the household decision process. Subsequently, this could then be used to (structurally) investigate the (un)observed heterogeneity of the impact of the policy intervention on the individual well-being of the recipients.

\section{References}

Almas, I., A. Armand, O. Attanasio, and P. Carneiro. 2018. "Measuring and Changing Control: Women's Empowerment and Targeted Transfers." Economic Journal 128:609-39.

Angelucci, M. 2008. "Love on the Rocks: Domestic Violence and Alcohol Abuse in Rural Mexico." B. E. Journal of Economic Analysis and Policy 8:1935-682.

. 2015. "Migration and Financial Constraints: Evidence from Mexico. Review of Economics and Statistics." Review of Economics and Statistics 97:224-28.

Angelucci, M., and R. Garlick. 2016. "Heterogeneity and Aggregation: Testing for Efficiency in Intra-Household Allocations." Working paper, University of Michigan and Duke University.

Angelucci, M., G. D. Giorgi, M. Rangel, and I. Rasul. 2009. "Village Economies and the Structure of Extended Family Networks." B. E. Journal of Economic Analysis and Policy 9:1-46.

Apps, P., and R. Rees. 1988. "Taxation and the Household.” Journal of Public Economics 35:199-219.

Attanasio, O., and V. Lechene. 2002. "Tests of Income Pooling in Household Decisions." Review of Economic Dynamics 5:720-48.

Attanasio, O., V. D. Maro, V. Lechene, and D. Phillips. 2013. "Welfare Consequences of Food Prices Increases: Evidence from Rural Mexico." Journal of Development Economics 104:136-51.

Attanasio, O. P., and V. Lechene. 2014. "Efficient Responses to Targeted Cash Transfers." Journal of Political Economy 122:178-222.

Baland, J. M., and R. Ziparo. 2018. "Intra-Household Bargaining in Poor Countries." In Towards Gender Equity in Development, ed. S. Anderson, L. Beaman, and J.-P. Platteau. Oxford: Oxford University Press.

Banks, J., R. Blundell, and A. Lewbel. 1997. "Quadratic Engel Curves and Consumer Demand." Review of Economics and Statistics 79:527-39. 
Barber, S. L., and P. J. Gertler. 2010. "Empowering Women: How Mexico's Conditional Cash Transfer Programme Raised Prenatal Care Quality and Birth Weight." Journal of Development Effectiveness 2:51-73.

Basu, K. 2006. "Gender and Say: A Model of Household Behaviour with Endogenously Determined Balance of Power." Economic Journal 116:558-80.

Behrman, J., and S. Parker. 2011. "The Impact of the PROGRESA/Oportunidades Conditional Cash Transfer Program on Health and Related Outcomes for the Aging in Mexico." PIER Working Paper Archive no. 11-032, Penn Institute for Economic Research, Department of Economics, University of Pennsylvania.

Blundell, R., P. Chiappori, and C. Meghir. 2005. "Collective Labor Supply with Children.” Journal of Political Economy 113:1277-306.

Blundell, R., and J. Robin. 1999. "Estimation in Large and Disaggregated Demand Systems: An Estimator for Conditionally Linear Systems." Journal of Applied Econometrics 14:209-32.

Bobonis, G. J. 2009. "Is the Allocation of Resources within the Household Efficient? New Evidence from a Randomized Experiment." Journal of Political Economy 117:453-503.

- 2011. "The Impact of Conditional Cash Transfers on Marriage and Divorce." Economic Development and Cultural Change 59:281-312.

Bobonis, G., R. Castro, and J. Morales. 2018. "Conditional Cash Transfers for Women and Spousal Violence: Evidence of the Long-Term Relationship from the Oportunidades Program in Rural Mexico.” IDB Working Paper no. 7267, Inter-American Development Bank, Washington, DC.

Bobonis, G. J., M. González-Brenes, and R. Castro. 2013. "Public Transfers and Domestic Violence: The Roles of Private Information and Spousal Control." American Economic Journal: Economic Policy 5:179-205.

Bourguignon, F., M. Browning, and P.-A. Chiappori. 2009. "Efficient Intra-Household Allocations and Distribution Factors: Implications and Identification." Review of Economic Studies 76:503-28.

Bourguignon, F., M. Browning, P.-A. Chiappori, and V. Lechene. 1993. "IntraHousehold Allocation of Consumption: A Model and Some Evidence from French Data." Annales d'Economie et de Statistique 29:137-56.

Browning, M., F. Bourguignon, P.-A. Chiappori, and V. Lechene. 1994. "Income and Outcomes: A Structural Model of Intrahousehold Allocation." Journal of Political Economy 102:1067-96.

Browning, M., and P. Chiappori. 1998. "Efficient Intra-Household Allocations: A General Characterization and Empirical Tests." Econometrica 66:1241-78.

Browning, M., P.-A. Chiappori, and A. Lewbel. 2013. "Estimating Consumption Economies of Scale, Adult Equivalence Scales, and Household Bargaining Power." Review of Economic Studies 80:1267-303.

Browning, M., P.-A. Chiappori, and Y. Weiss. 2014. Economics of the Family. Cambridge: Cambridge University Press.

Buse, A. 1994. "Evaluating the Linearized Almost Ideal Demand System." American Journal of Agricultural Economics 76:781-93.

- 1998. "Testing Homogeneity in the Linearized Almost Ideal Demand System." American Journal of Agricultural Economics 80:208-20. 
Cherchye, L., S. Cosaert, T. Demuynck, and B. De Rock. 2020. "Group Consumption with Caring Individuals.” Economic Journal 130, no. 627:587-622.

Cherchye, L., T. Demuynck, and B. De Rock. 2011. "Revealed Preference Analysis of Noncooperative Household Consumption.” Economic Journal 121:1073-96.

Cherchye, L., T. Demuynck, B. De Rock, and F. Vermeulen. 2017. "Household Consumption When the Marriage Is Stable." American Economic Review 107:1507-34.

Cherchye, L., B. De Rock, and F. Vermeulen. 2007. "The Collective Model of Household Consumption: A Nonparametric Characterization.” Econometrica 75: 553-74.

2009. "Opening the Black Box of Intrahousehold Decision Making: Theory and Nonparametric Empirical Tests of General Collective Consumption Models." Journal of Political Economy 117:1074-104.

. 2011. "The Revealed Preference Approach to Collective Consumption Behaviour: Testing and Sharing Rule Recovery." Review of Economic Studies 78:176-98.

Chiappori, P.-A. 1988. "Rational Household Labor Supply." Econometrica: Journal of the Econometric Society 56:63-90.

1992. "Collective Labor Supply and Welfare." Journal of Political Economy 100:437-67.

Chiappori, P.-A., and I. Ekeland. 2006. "The Micro Economics of Group Behavior: General Characterization.” Journal of Economic Theory 130:1-26.

- 2009. "The Microeconomics of Efficient Group Behavior: Identification." Econometrica 77:763-99.

Chiappori, P.-A., B. Fortin, and G. Lacroix. 2002. "Marriage Market, Divorce Legislation, and Household Labor Supply." Journal of Political Economy 110:37-72.

Chiappori, P.-A., and M. Mazzocco. 2017. "Static and Intertemporal Household Decisions." Journal of Economic Literature 55:985-1045.

Chiappori, P.-A., and J. Naidoo. 2020. "The Engel Curves of Non-Cooperative Households." Economic Journal 130:653-74.

d'Aspremont, C., and R. Dos Santos Ferreira. 2014. "Household Behavior and Individual Autonomy: An Extended Lindahl Mechanism." Economic Theory 55:643-64.

Dauphin, A., B. Fortin, and G. Lacroix. 2018. "Is Consumption Efficiency within Households Falsifiable?" Review of Economics of the Household 16:737-66.

Dercon, S., and P. Krishnan. 2000. "In Sickness and in Health: Risk Sharing within Households in Rural Ethiopia." Journal of Political Economy 108:688-727.

Donni, O. 2007. "Collective Female Labour Supply: Theory and Application.” Economic Journal 117:94-119.

Donni, O., and N. Moreau. 2007. "Collective Labor Supply: A Single-Equation Model and Some Evidence from French Data." Journal of Human Resources 42: 214-46.

Duflo, E. 2003. "Grandmothers and Granddaughters: Old-Age Pensions and Intrahousehold Allocation in South Africa." World Bank Economic Review 17:1-25.

Fiszbein, A., and N. R. Schady. 2009. Conditional Cash Transfers: Reducing Present and Future Poverty. Washington, DC: World Bank.

Fiszbein, A., N. R. Schady, and F. H. Ferreira. 2009. Conditional Cash Transfers: Reducing Present and Future Poverty. Washington, DC: World Bank. 
Fortin, B., and G. Lacroix. 1997. "A Test of Neoclassical and Collective Models of Household Labour Supply.” Economic Journal 107:933-55.

Gertler, P. 2004. "Do Conditional Cash Transfers Improve Child Health? Evidence from PROGRESA's Control Randomized Experiment." American Economic Review 94:336-41.

Hidrobo, M., and L. Fernald. 2013. "Cash Transfers and Domestic Violence.” Journal of Health Economics 32:304-19.

Hoddinott, J., and E. Skoufias. 2004. "The Impact of PROGRESA on Food Consumption." Economic Development and Cultural Change 53:37-61.

Kapan, T. 2010. "Property Division Laws: The Effects on Labor Supply and Household Bargaining." Meeting Paper no. 1127, Society for Economic Dynamics, Minneapolis.

Lechene, V., and I. Preston. 2011. "Noncooperative Household Demand.” Journal of Economic Theory 146:504-27.

Lewbel, A., and K. Pendakur. 2019. "Inefficient Collective Households: Abuse and Consumption." Working Papers in Economics 1000, Department of Economics, Boston College.

Matsuda, T. 2006. "Linear Approximations to the Quadratic Almost Ideal Demand System.” Empirical Economics 31:663-75.

Mazzocco, M. 2007. "Household Intertemporal Behaviour: A Collective Characterization and a Test of Commitment." Review of Economic Studies 74:857-95.

Moschini, G. 1995. "Units of Measurement and the Stone Index in Demand System Estimation." American Journal of Agricultural Economics 77:63-68.

Pashardes, P. 1993. "Bias in Estimating the Almost Ideal Demand System with the Stone Index Approximation.” Economic Journal 103:908-15.

Ramos, A. 2017. "Household Decision Making with Violence: Implications for Transfer Programs.” Working paper. https://sites.google.com/site/alejandraramos moreno/research.

Robinson, J. 2012. "Limited Insurance within the Household: Evidence from a Field Experiment in Kenya." American Economic Journal: Applied Economics 4:140-64.

Schultz, T. P. 2004. "School Subsidies for the Poor: Evaluating the Mexican PROGRESA Poverty Program.” Journal of Development Economics 74:199-250.

Skoufias, E. 2005. "PROGRESA and Its Impacts on the Welfare of Rural Households in Mexico." Research Report no. 139, International Food Policy Research Institute, Washington, DC.

Stecklov, G., P. Winters, M. Stampini, and B. Davis. 2005. "Do Conditional Cash Transfers Influence Migration? A Study Using Experimental Data from the Mexican PROGRESA Program.” Demography 42:769-90.

Thomas, D., D. Contreras, and E. Frankenberg. 2002. "Distribution of Power within the Household and Child Health." Santa Monica, CA: RAND.

Tommasi, D. 2017. "Control of Resources and Demand for Food." ECARES working paper, Université libre de Bruxelles.

Tommasi, D., and A. Wolf. 2016. "Overcoming Weak Identification in the Estimation of Household Resource Shares.” ECARES working paper 2016-12, Université libre de Bruxelles. 
Udry, C. 1996. "Gender, Agricultural Production, and the Theory of the Household." Journal of Political Economy 104:1010-46.

Vermeulen, F. 2005. "And the Winner Is. . .: An Empirical Evaluation of Unitary and Collective Labour Supply Models." Empirical Economics 30:711-34.

Walther, S. 2018. "Noncooperative Decision Making in the Household: Evidence from Malawi." Journal of Development Economics 134:428-42.

Yoong, J., L. Rabinovich, and S. Diepeveen. 2012. "The Impact of Economic Resource Transfers to Women versus Men.” Technical report, EPPI-Centre, London. 